\title{
A New Technique for Correction of Intussusception in Kankrej Bullock
}

\author{
J.B. Patel, Abhishek M. Patel", P.T. Sutaria, P.B. Patel and A.M. Patel \\ Department of Veterinary Surgery and Radiology, College of Veterinary Science \& Animal \\ Husbandry, S.D. Agricultural University, Sardarkrushinagar-385 506, Gujarat, India \\ *Corresponding author
}

\section{A B S T R A C T}

\section{Keywords}

Kankrej bullock, intussuscption,

Anastomosis,

banana,

Laparotomy

Article Info

Accepted:

18 February 2019

Available Online:

10 March 2019

\section{Introduction}

Intussusception is one of the most common causes of complete intestinal obstruction in animals (Pearson and Pinsent, 1977). The term refers to invagination or telescoping of part of intestine distally into adjacent portion. The invaginated portion is termed as "Intussusceptum" and the outer ensheathing portion is called "intussuscipiens". Intussusceptions are most common cause of intestinal obstruction in cattle and sheep (Tyagi and Singh, 1993). Sporadic occurrence in bovines has been documented (Pearson, 1971; Rathore et al., 1977 and Kumar et al., 2003). The present report describes a successful surgical management of intussusception in kankrej bullock.

\section{History and clinical symptoms}

A 7 years old Kankrej bullock was admitted to Dr. V. M. Jhala Clinical Complex, College of Veterinary Science and Animal Husbandry, S. D. A. U., Deesa with the history of off-feed and not passing faeces since last one week. The temperature and respiration rate were normal but heart rate little beat higher. The abdomen shows symmetrical bilateral distension. Per rectal examination revealed empty rectum with blood tinged mucus and sausage shaped hard mass was palpable near 
pelvic brim. Based on history and clinical examination the case was diagnosed as intussusception and planned for surgical correction.

\section{Materials and Methods}

In standing position right flank laparotomy was performed under local infiltration in inverted "L" block with $2 \%$ lignocaine. The intussusception mass was brought to the line of incision, the invagination observed the site of intussusception was in the colon of large intestine. Two intestinal clamps were applied on either side of the healthy part of intestine away from intussusception mass. Then intussuscepted mass was cut and intestine was cleaned with normal saline solution. The partially ripened banana dipped in $1 \%$ potassium permanganate solution was inserted intraluminal to get the lumen patency for suturing purpose so as overcome the difficulty in apposition of intestine and the intestinal continuity was restore by anastomosing the cut ends with cushing followed by lembert suture using 2-0 chromic catgut. The mesentery was sutured with continuous lockstitch suture. The half ripened banana was crushed intraluminal and anastomosed site was checked for leakage and intestine was repositioned into the abdomen. Powder Lixen was sprinkled into abdomen. Abdominal muscles and skin were closed as per usual manner. Post operatively Inj. DNS 2 litre IV, Inj. RL 1 litre IV, Inj. Oxytetracycline 50ml IV, Inj. Meloxicam 15 $\mathrm{ml}$ IV, Inj. Pheneramine Maleate $10 \mathrm{ml}$ IM and Vitamin B-complex $10 \mathrm{ml}$ IM were administrated for 5 days. Daily dressing of surgical wound with povidone-iodine and himax ointment was carried out till the complete healing.

\section{Results and Discussion}

Intussusception usually occurs in jejunam and ileum and rarely in colon the present report record intussusception in kankrej bullock rare occurrence. Hyper peristalsis and mechanical causes were considered to be the common factor for the intussusception (Pearson and Pinsent, 1977). Bowel inflammation or drinking of very cold water might cause hyper peristalsis. However a clear cause could not be established. Anorexia, colic and loss of rumination were the common symptom exhibited in intussusception of cattle (Fig. 1).

Fig.1

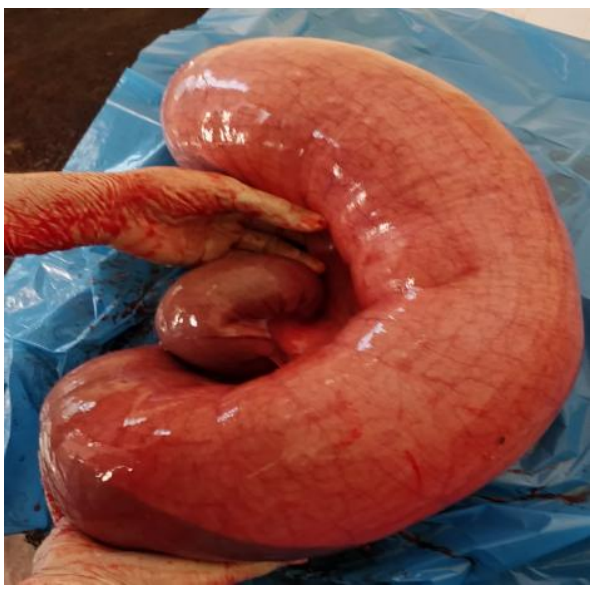


Normal temperature and heart rate, marked reduction in milk yield, bilateral distension of abdomen, ruminal atony and dehydration also were noticed (Sharma, 1997). Yadav (2006) reported that feeding and watering of animals after heavy work load is one of the predisposing factors for intussusception. Intussusception are surgically repaired by means of rejection and end to end anastomosis in both cattle and horses (Dabak et al., 2001; Fontaine-Rodgerson and Rodgerson, 2001), because end to end anastomosis causes less chances of stricture and leakage of surgical site (Constable et a., 1997).

This technique was preferred in two bullocks in addition to this half ripened banana was used to make the intraluminal patency and no complication was observed (Pitlawar et al., 2010). This approach is best to treat the case of intussusception successfully. Bullock passed faeces on next day operation and animal showed uneventful recovery.

In conclusion, the bullock having intussusception was brought for treatment and successfully treated by using partially ripened banana anastomosis technique.

\section{References}

Constable, P. D., St Jean, G., Hull, B. L., Rings, D. M., Morin, D. E., and Nelson, D. R.1997. Intussusception in cattle: 336 cases (1964-199). Journal of American Veterinary Medical Association. 210: 531-536.

Dabak, M., Unsaldi, E. and Gul, Y.2001. Diagnosis and treatment of intussusception in a cow. Turkish.
Journal of Veterinary Animal Science. 25: $387-89$.

Fontaine-Rodgerson, G. and Rodgerson, D. H.2001. Diagnosis of small intestinal intussusception by transabdominal ultra sonography in 2 adult horses. Canadian Veterinary Journal.42: 378-80.

Kumar, R., Lakkawar, A. W., Nair, M. G. and Varshney, K. C.2003. Gastro-intestinal obstruction in cows. Indian Veterinary Journal. 80: 318-19.

Pearson, H.1971. Intussusception in cattle. Vet Records. 89: 426-437.

Pearson, H. and Pinsent, H. J.1977. Intestinal obstruction in cattle. Vet. Records. 101:162- 66.

Pitlawar, S. S., Salunke V. M., Chaudhari, K. S., Yadav, G. U. and Sangame, A. D.2010. Management of intussusception in bullocks - new approach. Intas Polivet. 11(II): 220-221.

Rathore, S. S., Prasad, B., Singh, J. and Kumar, R. 1977. Intestinal obstruction in bovine- a report on four clinical cases. Indian Veterinary Journal. 54:573-75.

Sharma, S. P. 1997. Surgical correction of intussusception in bovine - A Report of 15 clinical cases. Indian Veterinary Journal 74: 607-08.

Tyagi, R. P. S. and Singh, J. 2007. A Textbook of Ruminant Surgery $3^{\text {rd }}$ edition. Pp: 216.

Yadav, G. U., Bhikane, A. U., Aher, A. D., Thorat, M. G., Markandeya and Masare, P. S. 2006. On standardization of diagnostic procedures and operative methodology in clinical cases of intussusception in bovines. Intas Polivet 10: $4-7$.

\section{How to cite this article:}

Patel, J.B., Abhishek M. Patel, P.T. Sutaria, P.B. Patel and Patel, A.M. 2019. A New Technique for Correction of Intussusception in Kankrej Bullock. Int.J.Curr.Microbiol.App.Sci. 8(03): 2108-2110. doi: https://doi.org/10.20546/ijcmas.2019.803.251 